DOI: 10.12731/2658-6649-2019-11-5-140-144

УДК 616.33-002.27

\title{
ПОКАЗАТЕЛИ КЛЕТОЧНОГО ИММУНИТЕТА В КРОВИ У БОЛЬНЫХ ХРОНИЧЕСКИМ И ХРОНИЧЕСКИМ АТРОФИЧЕСКИМ ГАСТРИТОМ
}

\author{
Смирнова О.В., Синяков А.А.
}

Helicobacter pylori является одной из распространенных причин возникновения хронических гастритов. В нашем исследовании мы изучили показатели клеточного иммунитета у больных хроническим гастритом и хроническим атрофическим гастритом на фоне Helicobacter pylori инфекиии. У больных с атрофическим гастритом тела желудка регистрировались изменения иммунного статуса, проявляющиеся в развитии вторичного иммунодефицита.

Ключевые слова: атрофический гастрит; клеточный иммунитет; лимфочитыты.

\section{INDICATORS OF CELLULAR IMMUNITY IN THE BLOOD OF PATIENTS WITH CHRONIC AND CHRONIC ATROPHIC GASTRITIS}

\author{
Smirnova O.V., Sinyakov A.A.
}

Helicobacter pylori is one of the common causes of chronic gastritis. In our study, we studied the indicators of cellular immunity in patients with chronic gastritis and chronic atrophic gastritis in the background of Helicobacter pylori infection. Patients with atrophic gastritis of the body of the stomach were recorded changes in the immune status, manifested in the development of secondary immunodeficiency.

Keywords: atrophic gastritis; cellular immunity; lymphocytes

\section{Введение}

Одним из распространенных заболеваний желудочно-кешечного тракта является хронический гастрит [1]. По данным Всемирной организации 
здравоохранения, около 80\% населения Земли страдают хроническим гастритом [2]. Многие авторы считают, что инфекция Helicobacter pylori (H. pylori) является одной из распространенных причин возникновения хронического гастрита. Степень выраженности хронического гастрита зависит от вирулентности штаммов H. pylori. Развитие атрофических изменений связывают с генетической предрасположенностью и индивидуальностью ответа на инфицирование $H$. pylori [3]. Структурные изменения слизистой оболочки, возникающие, при хроническом гастрите приводят к нарушению основных функций желудка [4]. Одной из важных эпидемиологических особенностей хронических гастритов является их предраковый потенциал. Целью данной работы было изучение показателей клеточного иммунитета у больных хроническим гастритом и хроническим атрофическим гастритом на фоне Helicobacter pylori инфекции.

\section{Материалы и методы}

В первую группу вошли 83 практически здоровых лиц (средний возраст $45,9 \pm 2,3$ года), во вторую группу - 77 пациентов с хроническим гастритом тела желудка (средний возраст 46,2+4,4 лет), в третью группу - 23 пациентов с выраженным атрофическим гастритом тела желудка (средний возраст 44,1+4,1 лет). Исследование проводилось с разрешения этического комитета «НИИ медицинских проблем Севера». Каждый участник подписывал форму информированного согласия на обследование, согласно Хельсинской Декларации Всемирной Медицинской Ассоциации, регламентирующей проведение научных исследований. Оценка клеточного звена иммунитета осуществлялась методом непрямойиммунофлюоресценции с помощью моноклональных антител в плазме крови [5]. Статистическая обработка данных осуществлялась с помощью пакета прикладных программ Statistica 7.0 (StatSoft, USA).

\section{Результаты исследования и обсуждения}

Относительные и абсолютные показатели клеточного иммунитета у больных ХАГ с H. pylori снижались по сравнению с группой больных ХГ и контрольной группой (в 1,2 раза для $\mathrm{CD} 3 \%$ ), (почти в 2 раза для $\mathrm{CD}^{+}$, $109 /$ ). Относительные показателя $\mathrm{CD}^{+}$-клеток у больных ХАГ с H. pylori была ниже в 1,5 раза по сравнению с группой больных ХГ и контрольной группой. Абсолютное количество $\mathrm{CD} 4^{+}$-лимфоцитов также была снижена у больных ХАГ с H. pylori в сравнении с группой больных ХГ и контрольной группы (в 1,4 раза). Абсолютное содержание CD8+-лимфоцитов уменьшалось в 1,6 раза у больных ХАГ с $H$. pylori относительно группы 
больных ХГ и контрольной группы. У больных ХАГ с H. pylori абсолютное содержание CD16 ${ }^{+}$клеток было снижено в 1,8 раз относительно контрольной группы.

\section{Заключение}

Снижение субпопуляций лимфоцитов, по данным некоторых авторов, происходит под действием индуцируемого Н. pylori апоптоза, что приводит к формированию иммунологической недостаточности. Сниженное количество лимфоцитов может быть обусловлено угнетением процессов лимфопролиферации, а причиной данного процесса можно рассматривать недостаточность активирующего сигнала, который связан с низким уровнем продукции активирующих цитокинов, либо с гиперпродукцией ингибирующих цитокинов. Таким образом, можно предположить неполноценность Т-хелперного звена иммунной защиты при активации супрессорной активности цитотоксических Т-лимфоцитов и возрастании содержания NK-клеток, для которых характерен неиммунный цитолиз.

Информация о конфликте интересов. Авторы заявляют об отсутствии конфликта интересов.

\section{Список литературы}

1. Blaser M.J. Hypothesis: the changing relationships of Helicobacter pylori and humans: implications for health and disease. J Infect Dis 1999; 179: 1523-1530.

2. Александрова В.А. Сравнительный анализ методов определения Helicobacter pylori у детей / В.А. Александрова, А.Б. Жебрун, Л.Б. Гончарова // Актуальные проблемы абдоминальной патологии у детей. 2001. С. 80-84.

3. Бордин Д.С. Хронический гастрит: современный взгляд на старую проблему / Д.С. Бордин, А.А. Машарова, С.Г. Хомерики // Сучасна Гастроентерологія. 2013. № 1 (69). С. 72-79.

4. Прихода И.В. Иммунологическая реактивность при хроническом гастрите / И.В. Прихода, М.М. Терещенко // Луганский национальный университет имени Тараса Шевченко. 2009. С. $2-5$.

5. Агеева Е.С. Роль нарушений системы цитокинов в патогенезе Helicobacter pylori-ассоциированной патологии / Е.С. Агеева, О.В. Штыгашева, В.М. Иптышев и др. // Бюллетень сибирской медицины. 2011. № 6. С. 5-9.

6. Терапевтические аспекты лечения язвенных кровотечений. Маев И.В., Цуканов В.В., Третьякова О.В., Каспаров Э.В. и др. Фарматека. 2012. № 2 (235). C. 56-59. 
7. Особенности хемилюминесцентной активности нейтрофильных гранулоцитов больных механической желтухой доброкачественного генеза. Смирнова О.В., Титова Н.М., Елманова Н.Г. Российский иммунологический журнал. 2015. Т. 9(18). № 2-1. С. 313-315.

\section{References}

1. Blaser M.J. Hypothesis: the changing relationships of Helicobacter pylori and humans: implications for health and disease. J Infect Dis 1999; 179: 1523-1530.

2. Aleksandrova V.A., ZHebrun A.B., Goncharova L.B. Sravnitel'nyj analiz metodov opredeleniya Helicobacter pylori u detej [Comparative analysis of methods for the determination of Helicobacter pylori in children]. Aktual'nye problemy abdominal'noj patologii u detej [Actual problems of abdominal pathology in children]. 2001, pp. 80-84.

3. Bordin D.S., Masharova A.A., Homeriki S.G. Hronicheskij gastrit: sovremennyj vzglyad na staruyu problem [Chronic gastritis: a modern look at the old problem]. Suchasna Gastroenterologiya [Modern Gastroenterology]. 2013. № 1 (69), pp. 72-79.

4. Prihoda I.V., Tereshchenko M.M. Immunologicheskaya reaktivnost'pri hronicheskom gastrite [Immunological reactivity in chronic gastritis]. Lugansk National University named after Taras Shevchenko. 2009, pp. 2-5.

5. Ageeva E.S., Shtygasheva O.V., Iptyshev V.M. et al. Rol' narushenij sistemy citokinov v patogeneze Helicobacter pylori-associirovannoj patologii [The role of cytokine disorders in the pathogenesis of Helicobacter pylori-associated pathology]. Byulleten'sibirskoj mediciny [Bulletin of Siberian medicine]. 2011. № 6, pp. 5-9.

6. Maev I.V., Cukanov V.V., Tret'yakova O.V., Kasparov E.V. et al. Terapevticheskie aspekty lecheniya yazvennyh krovotechenij [Therapeutic aspects of the treatment of ulcerative bleeding]. Farmateka [Farmateka]. 2012. № 2 (235), pp. 56-59.

7. Smirnova O.V., Titova N.M., Elmanova N.G. Osobennosti hemilyuminescentnoj aktivnosti nejtrofil'nyh granulocitov bol'nyh mekhanicheskoj zheltuhoj dobrokachestvennogo geneza [Features of the chemiluminescent activity of neutrophilic granulocytes in patients with obstructive jaundice of benign genesis]. Rossijskij immunologicheskij zhurnal [Russian immunological journal]. 2015. V. 9(18). № 2-1, pp. 313-315.

\section{ДАННЫЕ ОБ АВТОРАХ}

Смирнова Ольга Валентиновна, д.м.н., доцент, профессор, заведующая лабораторией клинической патофизиологии Федеральное государственное бюджетное научное учреждение «Федеральные исследовательский иентр «Красноярский научный 
центр Сибирского отделения Российской академии наук»-обособленное подразделение «Научно-исследовательский институт медицинских проблем Севера»

ул. Партизана Железняка, 32, г. Красноярск, 660022, Российская Федерация

ovsmirnova71@mail.ru

Синяков Александр Александрович, к.б.н., младший научный сотрудник лаборатории клинической патофизиологии

Федеральное государственное бюджетное научное учреждение «Федеральные исследовательский иентр «Красноярский научныии иентр Сибирского отделения Российской академии наук»-обособленное подразделение «Научно-исследовательский институт медищинских проблем Севера»

ул. Партизана Железняка, 32, г. Красноярск, 660022, Российская Федерация

sinyakov.alekzandr@mail.ru

\section{DATA ABOUT THE AUTHORS}

Smirnova Olga Valentinovna, Doctor of Medical Sciences, Associate Professor, Professor, Head laboratory of clinical pathophysiology

Research Institute of Medical Problems of the North of the Federal Research Center Krasnoyarsk Scientific Center of the Siberian Branch of the Russian Academy of Sciences

3g, Partizan Zheleznyak Str., Krasnoyarsk, 660022, Russian Federation ovsmirnova71@mail.ru

Sinyakov Alexander Alexandrovich, Ph.D., Junior Researcher, Clinical Pathophysiology

Research Institute of Medical Problems of the North of the Federal Research Center Krasnoyarsk Scientific Center of the Siberian Branch of the Russian Academy of Sciences

3g, Partizan Zheleznyak Str., Krasnoyarsk, 660022, Russian Federation sinyakov.alekzandr@mail.ru 